\title{
Overexpression of xeroderma pigmentosum group C decreases the chemotherapeutic sensitivity of colorectal carcinoma cells to cisplatin
}

\author{
YI ZHANG, JIA CAO, YANNI MENG, CHUNYING QU, FENG SHEN and LEIMING XU \\ Department of Digestive Endoscopic Diagnosis and Treatment, Xinhua Hospital, School of Medicine, \\ Shanghai Jiaotong University, Shanghai 200092, P.R. China
}

Received November 12, 2016; Accepted November 20, 2017

DOI: $10.3892 / \mathrm{ol} .2018 .8127$

\begin{abstract}
Xeroderma pigmentosum group C (XPC) is a DNA-damage-recognition gene active at the early stage of DNA repair. XPC also participates in regulation of cell-cycle checkpoint and DNA-damage-induced apoptosis. In the present study, the expression levels of genes involved in nucleotide excision repair (NER) were assessed in human colorectal cancer (CRC) tissue. This analysis revealed that expression of XPC mRNA significantly increased in colorectal carcinoma tissues compared with matched normal controls. Expression of XPC gradually increased along with the degree of progression of CRC. In vitro, an XTT assay demonstrated that small interfering RNA (siRNA) targeting XPC significantly increased the sensitivity of CRC SW480 cells to cisplatin, whereas cells transfected with a XPC-overexpression plasmid became more resistant to cisplatin. Furthermore, flow cytometry revealed that the proportion of apoptotic cells significantly increased in XPC-knockdown cells upon cisplatin treatment. However, the overexpression XPC significantly increased the resistance of cells to cisplatin. In vivo, tumor growth was significantly reduced in tumor-bearing mice when the XPC gene was knocked down. Upregulation of the expression of pro-apoptotic Bcl-associated $\mathrm{X}$ and downregulation of the anti-apoptotic B-cell lymphoma 2 proteins was observed in the implanted tumor tissue. In conclusion, XPC serves a key role in chemotherapeutic sensitivity of CRC to cisplatin, meaning that it may be a potential target for chemotherapy of CRC.
\end{abstract}

Correspondence to: Dr Leiming Xu, Department of Digestive Endoscopic Diagnosis and Treatment, Xinhua Hospital, School of Medicine, Shanghai Jiaotong University, 1665 Kongjiang Road, Yangpu, Shanghai 200092, P.R. China

E-mail: lming_xu@163.com

Key words: colorectal carcinoma, nucleotide excision repair xeroderma pigmentosum group $\mathrm{C}$, cisplatin, apoptosis

\section{Introduction}

Genomic DNA is sensitive to a variety of exogenous damage, including hydrolysis, oxidation, mismatch, and endogenous damages such as UV radiation and chemicals. Endogenous damage can also result in gene disruption and deletion, ultimately causing apoptosis or tumorigenesis $(1,2)$.

Abnormal DNA repair is closely associated with tumorigenesis and tumor multi-drug resistance (3). Nucleotide excision repair (NER) is one of the primary defensive barriers against tumorigenesis and a major repair system for chemotherapy-induced DNA damage. Chemotherapy is widely applied to induce apoptosis of tumor cells $(1,4,5)$. Thus, NER reduces the efficacy of chemotherapy to a certain degree.

NER is comprised of two pathways: Global genome repair (GGR) and transcription-coupled repair (TCR). GGR is involved in injury repair for any genomic sequence, which is crucial to prevent carcinogenesis (6). The major role of TCR is to delay aging by repairing the DNA damage present in activated transcriptional chains (2). Generally, the NER process is divided into the following three steps: i) Damage recognition and shear complex assemble; ii) double-stranded DNA separation and damage removal; and iii) DNA repair synthesis and double-strand linkage. During the whole process, the recognition of DNA damage is required to trigger and initiate the following repair via certain signal transduction pathways (7).

Among these NER genes, xeroderma pigmentosum gene group $\mathrm{C}$ (XPC) serves a key role in the process of GGR $(1,2,8,9)$. Neither GGR nor TCR can be initiated in the absence of XPA $(10,11)$. XPF combines with DNA excision repair protein ERCC-1 (ERCC1) to form a dimer that functions as a $5^{\prime}$ DNA endonuclease, whereas XPG functions as a DNA ligase and a $3^{\prime}$ DNA endonuclease $(1,2,8)$.

Previous studies have demonstrated that the NER genes are associated with the genesis and development of tumors (12-15). Huang et al (14) revealed that haplotypes of XPC polymorphisms containing XPC $499 \mathrm{~V}$ modified the smoking-associated risks of advanced colorectal adenoma. Previously, it has been confirmed that there is no significant relation between XPD genetic variation and non-Hodgkin's lymphoma (NHL) risk (12). However, the presence of the XPD 751Gln allele was identified to be associated with a 
two-fold decreased risk of developing diffuse large B-cell lymphoma (12).

In the present study the expression levels of the NER genes XPC, XPA, XPG, XPF, ERCC1 and XPD were determined in human colorectal carcinoma (CRC) and corresponding normal tissues. The role of differential genes in chemotherapeutic resistance of CRC was investigated. In view of this, the present study aimed to clarify the role of these NER genes in the chemotherapeutic sensitivity of CRC, and provide evidence of the efficacy of targeting these genes in the treatment of CRC clinically in the future.

\section{Materials and methods}

Clinic data and specimens collection. A total of 46 samples of fresh CRC and 20 samples of adjacent normal colorectal tissues were obtained from Department of General Surgery, Xinhua Hospital (Shanghai, China) between January 2014 and May 2015. The patient cohort included 25 males and 21 females. The mean age of the patients was $58.4 \pm 14.8$ years old. All patients underwent surgical resection and cisplatin chemotherapy. The specimens included 10 cases of mucinous adenocarcinoma, 22 cases of adenocarcinoma and 14 cases of mucinous adenocarcinoma complicated with adenocarcinoma.

All patients were diagnosed as having CRC following biopsy. The adjacent tissue that was 5-cm away from the CRC was removed and selected as a normal control, which was also confirmed by pathological examination. All patients provided written informed consent. This study was approved by the Ethics Committee of Xinhua Hospital.

Main reagents. TRIzol reagent and reverse transcriptase M-MLV were purchased from Invitrogen; Thermo Fisher Scientific, Inc. (Waltham, MA, USA). Quantitative PCR reagents $\mathrm{IQ}^{\mathrm{TM}} \mathrm{SYBR}^{\circledR}$-Green I Supermix was obtained from Bio-Rad Laboratories, Inc. (Hercules, CA, USA). An Annexin V-Fluorescein isothiocyanate (FITC) apoptosis assay kit was provided by Beijing Baosai Biological Technology Co., Ltd. (Beijing, China). A Silencer T small interfering RNA (siRNA) construction kit was obtained from Ambion; Thermo Fisher Scientific, Inc. Cisplatin was provided by Sigma-Aldrich; Merck KGaA (Darmstadt, Germany). The primers for XPC, XPA, XPG, XPF, ERCC1, and XPD (Table I) were synthesized by Takara Biotechnology Co., Ltd. (Dalian, China).

A plasmid, which carried an XPC gene cDNA, was constructed in our laboratory according to protocols described previously $(16,17)$. Following SfiI digestion, the XPC gene cDNA was further removed from the plasmid and then inserted into the SfiI site of pcDNA3.1(+) (Invitrogen; Thermo Fisher Scientific, Inc.) to prepare the pcDNA3-XPC plasmid.

Cell line and culture condition. The CRC HCT116, HCT8, HT29, LS174T, LOVO, SW480, SW620 cell lines and the normal human colorectal FHC cell line were provided by the Type Culture Collection of the Chinese Academy of Sciences (Shanghai, China). All the cell lines were cultured in RPMI-1640 medium supplemented with $10 \%$ fetal bovine serum and cultured at $37^{\circ} \mathrm{C}$ in an atmosphere of $5 \% \mathrm{CO}_{2}$. When the cells reached a confluence of $\sim 90 \%$ (every $\sim 3$ days), they were passaged. Cells at passages 3-5 were used for experimental analyses.
Reverse transcription-quantitative polymerase chain reaction $(R T-q P C R)$. Total RNA was extracted from normal and CRC tissues or cancer cells using TRIzol. Total RNA preparation was performed in accordance with the manufacturer's protocol. Following DNase I (Takara Biotechnology Co., Ltd., Dalian, China) treatment, $2 \mu \mathrm{g}$ of RNA was reverse transcribed using a Takara RNA LA PCR kit (AMV) (Takara Biotechnology Co., Ltd.).

The $25 \mu \mathrm{l}$ standard reaction system included $12.5 \mu \mathrm{l}$ of Real-Time PCR Master Mix SYBR-Green I, $0.5 \mu \mathrm{l}$ of primer forward $(10 \mu \mathrm{mol} / \mathrm{l}), 0.5 \mu \mathrm{l}$ of primer reverse $(10 \mu \mathrm{mol} / \mathrm{l}), 1 \mu \mathrm{l}$ of cDNA and $10.5 \mu \mathrm{l}$ of $\mathrm{ddH}_{2} \mathrm{O}$. The sequences of all primers are listed in Table I. The reaction condition included initial denaturation at $95^{\circ} \mathrm{C}$ for $3 \mathrm{~min}$, then denaturation at $95^{\circ} \mathrm{C}$ for $4.5 \mathrm{~min}$, annealing at $60^{\circ} \mathrm{C}$ for $40 \mathrm{sec}$ and extension at $72^{\circ} \mathrm{C}$ for $40 \mathrm{sec}$. The following reactions were performed for 40 cycles. The data were analyzed using iQ5 Gene expression software (Bio-Rad Laboratories, Inc.). The reactions were performed and values were normalized to the housekeeping gene GAPDH, $\mathrm{C}_{\mathrm{q}}$ values were determined by using the 7500 System SDS software (version.1.2.3; Applied Biosystems; Thermo Fisher Scientific, Inc.). Expression ratios were calculated using the $2^{-\Delta \Delta \mathrm{Cq}}$ method (18).

Western blot assay. Approximately $100 \mathrm{mg}$ of the cancer cells were lysed with $1 \mathrm{ml}$ of pre-cooled radioimmunoprecipitation assay buffer containing $150 \mathrm{mM} \mathrm{NaCl}, 1.0 \% \mathrm{NP}-40$ or $0.1 \%$ Triton $\mathrm{X}-100,0.5 \%$ sodium deoxycholate, $0.1 \%$ SDS (sodium dodecyl sulphate), $50 \mathrm{mM}$ Tris- $\mathrm{HCl}$ ( $\mathrm{pH} 8.0)$ and protease inhibitors (Abcam, Cambridge, UK) for $15 \mathrm{sec}$ and then in an ice bath for another $10 \mathrm{~min}$. The lysate was then centrifuged at $12,000 \mathrm{x} \mathrm{g}$ at $4^{\circ} \mathrm{C}$ for $10 \mathrm{~min}$ and the supernatant was harvested. The concentration of the total protein was quantified using the Bradford method.

A total of $50 \mu \mathrm{g}$ protein per lane was separated by $12 \%$ SDS-PAGE and then the proteins were transferred onto a polyvinylidene fluoride transfer membrane. The transfer membrane was semidried at $20 \mathrm{~V}$ for $15 \mathrm{~min}$. The membrane was then blocked with $5 \%$ skim milk for $4 \mathrm{~h}$ at $4^{\circ} \mathrm{C}$. The membranes were washed three times with TBS for $5 \mathrm{~min}$ each. Subsequently, goat anti-human XPC polyclonal antibody (Santa Cruz Biotechnology, Inc., Dallas, TX, USA; 1:200) was added and the membranes were incubated at $4^{\circ} \mathrm{C}$ overnight. Next, horseradish peroxidase-conjugated rabbit anti-goat IgG (cat. no. TA130025; Origene Technologies, Inc., Beijing, China; 1:3,000) was added and incubated at room temperature for another $2 \mathrm{~h}$. The membrane was stained with Enhanced Chemiluminescence reagent (Pierce; Thermo Fisher Scientific,Inc.) and imaged on X-ray film (Fujifilm Corporation, Tokyo, Japan) by autoradiography. Quantity One ${ }^{\circledR}$ 1-D analysis software (Bio-Rad Laboratories, Inc.) were used to quantitatively analyze the density of the bands. $\beta$-actin (cat. no. Ab8227; Abcam, Cambridge, UK; 1:1,000) was selected as an internal control. The relative protein level was expressed as a ratio between the densities of XPC and $\beta$-actin.

Immunohistochemistry analysis. A total of 46 specimens (25 males and 21 females; $58.4 \pm 14.8$ years old) were used for this experiment. Archived samples from these 36 cases were retrieved from the surgical pathology files. These CRC tissues, according to the Vienna modified classification (2002) (19), were assigned 
Table I. Reverse transcription-quantitative polymerase chain reaction primer pairs for nucleotide excision repair genes.

\begin{tabular}{llcl}
\hline Gene & \multicolumn{1}{c}{ Primer pairs } & Product size, bp \\
\hline GAPDH & F: & 5'-CTCTCTGCTCCTCCTGTTCGAC-3' \\
XPA & R: & 5'-TGAGCGATGTGGCTCGGCT-3' \\
& F: & 5'-GGTCTCTTGAAGTTTGGGGTAGTC-3' \\
XPC & R: & 5'-TTCCACACGCTGCTTCTTACTG-3' \\
& F: & 5'-ACACCTACTACCTCTCAAACC-3' \\
XPD & R: & 5'-ATGGACCAATTCCTCATCATCTCG-3' \\
& F: & 5'-GCCTGAACGCTCTTCTAA-3' \\
XPF & R: & 5'-TTACAGGCGGTGGCGATAAT-3' \\
& F: & 5'-TTTGTGAGGAAACTGTATCTGTGG-3' \\
XPG & R: & 5'-GTCTGTATAGCAAGCATGGTAGG-3' \\
& F: & 5'-AGGTAGAGTCAAGGAGAGT-3' \\
ERCC1 & R: & 5'-TGCTCCTGTCATTGTTGTA-3' \\
& F: & 5'-CTGCTGCGGGATGAGAAC-3' \\
& R: & 5'-ATCGGAATAAGGGCTTGGC-3' \\
\hline
\end{tabular}

XPA, xeroderma pigmentosum group A; ERCC1, DNA excision repair protein ERCC-1; F, forward; R, reverse.

pathologically to poor differentiated (11 cases), moderately differentiated (20 cases) and highly differentiated (15 cases).

The 5- $\mu \mathrm{m}$ tissue sections were deparaffinized with xylene, rehydrated in graded alcohol, and processed using the streptavidin immunoperoxidase method. Briefly, the sections were submitted to antigen retrieval by heating to $95^{\circ} \mathrm{C}$ for $10 \mathrm{~min}$ in a citrate buffer $(0.01 \mathrm{~mol} / \mathrm{l}, \mathrm{pH} 6.0)$. Subsequently, the slides were incubated in $10 \%$ goat normal serum (cat. no. C-0005; Shanghai Haoran Biotechnology Co., Ltd., Shanghai, China) for $30 \mathrm{~min}$ at room temperature, followed by overnight incubation at $4^{\circ} \mathrm{C}$ with goat anti-human XPC polyclonal antibody (Santa Cruz Biotechnology, Inc.; 1:100). Following this, the samples were incubated with biotinylated rabbit anti-goat immunoglobulin G (cat. no. ZDR-5308; Beijing Zhongshan Golden Bridge Biotechnology Co., Ltd., Beijing, China; 1:2,000) for $15 \mathrm{~min}$ at $37^{\circ} \mathrm{C}$, followed by streptavidin peroxidase complexes (cat. no. SP Kit-D1; Beijing Dingguo Changsheng Biotechnology Co., Ltd., Beijing, China) for $15 \mathrm{~min}$ at $37^{\circ} \mathrm{C}$. 3, 3'-diaminobenzidine was used as a chromogen, and hematoxylin was used for nuclear counterstaining for $10 \mathrm{~min}$ at room temperature. Following this, immunostaining was quantified using a CM-2000B imaging analysis system (Beijing University of Aeronautics and Astronautics, Beijing, China). Identification of immunohistochemistry results was in accordance to the criteria proposed by Maruyama et al (20). The differences between the two random groups were analyzed using $\chi^{2}$ test.

Plasmid construction of siRNA targeting XPC. An effective sequence targeting XPC (5'-GGATGAAGCCCTCAG CGAT-3') was screened using GenBank (no. NM_004628; https://www.ncbi.nlm.nih.gov/nuccore/NM_004628.4). As a template, the oligonucleotide chains were designed based on the base pairing rule.

The following nucleotide sequences were used: Forward, 5'-GATCCGGATGAAGCCCTCAGCGATTTCAAGAGAA 'TCGCTGAGGGCTTCATCCTTTTTTGGAA-3' and reverse,
5'-AGCTTTTCCAAAAAAGGATGAAGCCCTCAGCGAT TCTCTTGAAATCGCTGAGGGCTTCATCCG-3'.

The control sequences forward, 5'-GATCCGGATGAA GCCCTCAGCGATTTCAAGAGAGTGCACCGAGTCCTT CTGTATTTTTGGAAA-3' and reverse, 5'-AGCTTTTCC AAAAAATTACAGAAGGACTCGGTGCACTCTCTTGAA ATCGCTGAGGGCTTCATCCG-3' were also selected. The oligonucleotides were synthesized by Invitrogen; Thermo Fisher Scientific, Inc.

A pSilencer ${ }^{\mathrm{TM}}$ 5.1-H1 Retro Vector (Ambion, No. AM5784) was digested using HindIII and BamHI restriction enzymes, followed by ligation with T4 DNA ligase. Next, the recombinant plasmid was transformed into fresh competent E. Coli DH5a cells. The recombinant clones were selected from a Luria-Bertani agar plate containing $100 \mu \mathrm{g} / \mathrm{ml}$ ampicillin. The positive clones were confirmed by PCR and then sent to Shanghai GeneChem Co.,Ltd. (Shanghai, China) for sequencing. The confirmed vector was named pSilencer ${ }^{\mathrm{TM}}$ 5.1-XPC siRNA and the control vector was named pSilencer ${ }^{\mathrm{TM}}$ 5.1-XPC control. Lipofectamine ${ }^{\circledR} 2000$ (Invitrogen; Thermo Fisher Scientific, Inc.) was used together with pSilencer ${ }^{\mathrm{TM}}$ 5.1-XPC siRNA $(20 \mu \mathrm{g} / \mu \mathrm{l})$ or $\mathrm{pSSilencer}^{\mathrm{TM}}$ 5.1-XPC control $(20 \mu \mathrm{g} / \mu \mathrm{l})$ to transfect SW480 cells for $20 \mathrm{~min}$. Additional puromycin $(0.4 \mu \mathrm{g} / \mathrm{ml})$ was added to screen the positive clones $48 \mathrm{~h}$ following transfection.

Stable transfection of CRC cells with siRNA-XPC or pcDNA3-XPC plasmid. SW480 cells were seeded in $100-\mathrm{mm}$ cell culture dishes and cultured to reach a confluence of $70-80 \%$. The cells were then transfected with the siRNA-XPC $(0.2 \mu \mathrm{g} / \mu \mathrm{l})$ or the pcDNA3-XPC plasmid DNA using a cationic lipid $(0.2 \mu \mathrm{g} / \mu \mathrm{l})(10 \mu \mathrm{g}$ of plasmid DNA/50 $\mu \mathrm{l}$ Lipofectamine 2000/100-mm dish) for $6 \mathrm{~h}$. As a control, cells were transfected with the pcDNA3.

Cell susceptibility assay. The treated SW480 cells $\left(1 \times 10^{6} / \mathrm{ml}\right)$ were inoculated in a 96-well plate $(100 \mu \mathrm{l} /$ well) and treated 
with cisplatin (5 $\mu \mathrm{mol} / \mathrm{l})$ (cat. no. 479306-1G; Sigma-Aldrich; Merck KGaA, Darmstadt, Germany) for $4 \mathrm{~h}$. Cell susceptibility was measured at $24 \mathrm{~h}$ upon the addition of the tetrazolium salt XTT $(0.12 \mathrm{mg} / \mathrm{ml})$ to the culture medium. The concentration of formazan dye formed was measured by at $492 \mathrm{~nm}$ using a microplate reader (Bio-Rad Laboratories, Inc.).

Cell apoptosis assay. The SW480 cells were treated with $5 \mu \mathrm{mol} / \mathrm{l}$ cisplatin for $4 \mathrm{~h}$. Subsequently, the cells were digested with $0.1 \%$ trypsin. Next, the cell suspension was centrifuged at $150 \mathrm{x} \mathrm{g}$ for $5 \mathrm{~min}$ at $4^{\circ} \mathrm{C}$ and the cells were harvest. The supernatant was removed and the precipitate was washed twice with PBS. The SW480 cells were resuspended in PBS and adjusted to a concentration of $1 \times 10^{6} / \mathrm{ml}$.

A total of $100 \mu \mathrm{l}$ Annexin-V-FITC reagent was added to the cells for 10-15 min at room temperature in the dark. Cells were then centrifuged at $150 \mathrm{x}$ g for $5 \mathrm{~min}$ at $4^{\circ} \mathrm{C}$ and washed with PBS once. Cell apoptosis was then detected using a flow cytometer. The data were analyzed using CellQuest 3.0 software (BD Biosciences, Franklin Lakes, NJ, USA).

Establishment of a xenograft tumor model of human CRC. In total, 24 male BALB/c nude mice (Silaike Experimental Animal Center, Shanghai, China; http://www.lascn. net/SupplyDemand/Site/Contact.aspx?id=77) (weight, 18-22 g) aged 6-7 weeks, were subcutaneously inoculated with $0.2 \mathrm{ml}$ of the prepared SW480 cell suspension $\left(1 \times 10^{7} / \mathrm{ml}\right)$. The mice had free access to food and water, and were maintained in a room at $20-22^{\circ} \mathrm{C}, 40-70 \%$ humidity and a $12 \mathrm{~h}$ light/dark cycle.

Following this, the general conditions of the animals, including consciousness, diet and activity, were observed and recorded. Tumor volume was also observed successively for 14 days and recorded at particular time points to plot a growth curve. Tumor volume (TV) and relative TV (RTV) were calculated as follows: $\mathrm{TV}=1 / 2 \times \mathrm{ax} \mathrm{b}^{2}(\mathrm{a}, \mathrm{b}$ represent long and short diameter of the tumor tissue, respectively); $\mathrm{RTV}=\mathrm{V}_{\mathrm{t}} / \mathrm{V}_{0}$ $\left(\mathrm{V}_{\mathrm{t}}\right.$ represents the tumour volume at different measurement time points, $\mathrm{V}_{0}$ represents original tumour volume at day 0 ). All experiments were conducted in accordance with the National Guidelines for the Care and Use of Laboratory Animals. This study was approved by the Ethics Committee of Xinhua Hospital.

Western blotting assay of B-cell lymphoma-2 (Bcl-2) and Bcl-associated X (Bax) protein expression levels in transplanted tumor tissue. At the end of the experiment, the animals were sacrificed and the implanted tumor tissues were isolated and homogenized. Bax (1:200; cat. no. ab53154; Abcam) and Bcl-2 (1:200; cat. no. ab59348; Abcam) protein expression was measured by western blotting at $4^{\circ} \mathrm{C}$ overnight. The rabbit anti-goat immunoglobulin G (1:2,000; cat. no. ZDR-5308; Beijing Zhongshan Golden Bridge Biotechnology Co., Ltd.) was used as a secondary antibody at room temperature for $2 \mathrm{~h}$.

Statistical analysis. All the data are expressed as mean \pm standard deviation. SPSS 17.0 statistics software (SPSS, Inc., Chicago, IL, USA) was used to analyze differences. The $\chi^{2}$ test was used to compare the expression of XPC in cancer tissues with different degrees of differentiation. One-way analysis of variance assay followed by Dunnett's least significant
Table II. Expression of XPC in caner tissue with different degrees of differentiation.

\begin{tabular}{lrcc}
\hline Differentiation degree & $\mathrm{XPC}^{-}, \mathrm{n}$ & $\mathrm{XPC}^{+}, \mathrm{n}$ & Total, $\mathrm{n}$ \\
\hline Poor & 3 & 8 & 11 \\
Moderate & 12 & $8^{\mathrm{a}}$ & 20 \\
High & 12 & $3^{\mathrm{a}, \mathrm{b}}$ & 15 \\
\hline
\end{tabular}

The difference between the two random groups was analyzed using $\chi^{2}$ test. ${ }^{\mathrm{a}} \mathrm{P}<0.01$ vs. poorly differentiated; ${ }^{\mathrm{b}} \mathrm{P}<0.01$ vs. moderately differentiated. $\mathrm{XPC}^{-}$, negative expression of xeroderma pigmentosum group $\mathrm{C}$.

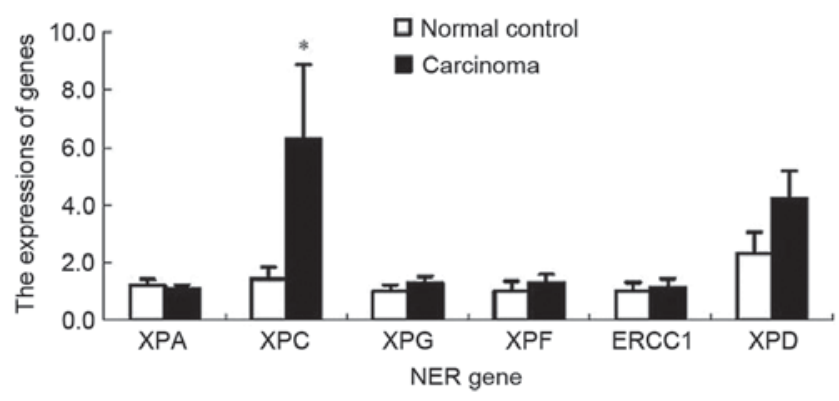

Figure 1. Expression of NER genes between normal and cancerous colorectal tissues. ${ }^{*} \mathrm{P}<0.01$ vs. normal control. NER, nucleotide excision repair; XPC, xeroderma pigmentosum group C; ERCC1, DNA excision repair protein ERCC-1.

difference and a paired Student's t-test was used to compare the difference among and between groups, respectively. $\mathrm{P}<0.05$ was considered to indicate a statistically significant difference.

\section{Results}

XPC mRNA expression is upregulated in CRC tissue. RT-qPCR analysis revealed that only expression of XPC mRNA in the $\mathrm{CRC}$ tissue was significantly increased compared with that in the normal colorectal tissue $(\mathrm{P}<0.01)$. However, there were no significant differences in the mRNA expression of other NER genes, including XPA, XPG, XPF, ERCC1 and RAP1 between the cancerous and normal tissues $(\mathrm{P}>0.05$; Fig. 1$)$.

$X P C$ expression is associated with the malignancy of $C R C$. The results of immunohistochemistry indicated that the XPC-positive expression was present in $72.7 \%$ of the poorly differentiated samples $(8 / 11), 40.0 \%$ of the moderately differentiated samples $(8 / 20)$ and $20.0 \%$ of highly differentiated samples (3/15) (Table II). The differences between the two random groups were analyzed using $\chi^{2}$ test. XPC expression was the highest in the poorly differentiated samples, then in the moderately differentiated and lowest in the highly differentiated cancerous tissues (Fig. 2). These results indicated that the XPC expression was associated with the degree of malignancy in CRC.

XPC mRNA expression is highest in the SW480 cell line. The level of XPC mRNA expression was significantly increased in HT29, LOVO, and SW480 cell lines compared with the FHC cell line. XPC mRNA was expressed at the highest level in 


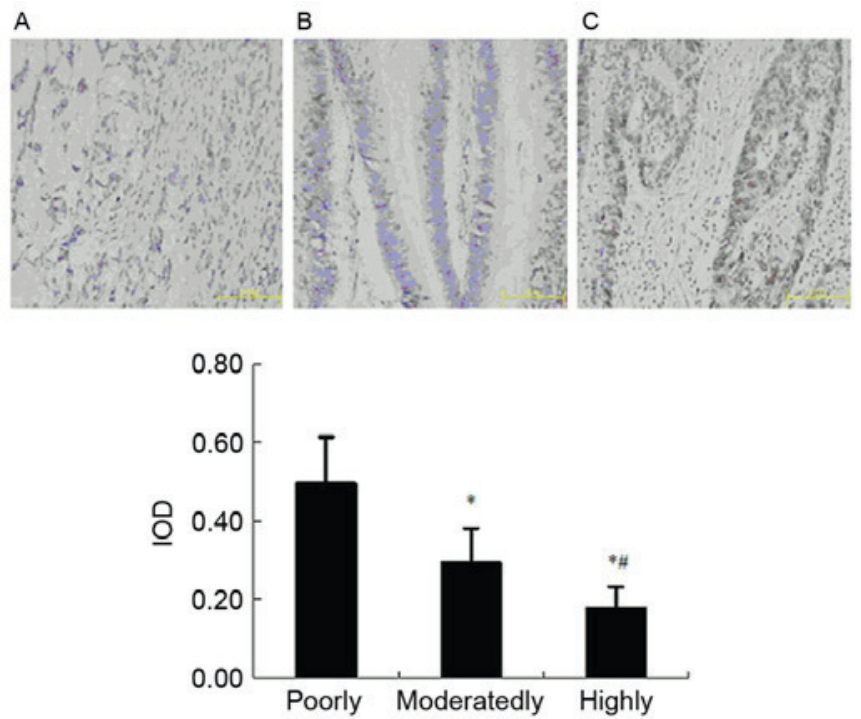

Figure 2. XPC-positive expression integrated option density in the CRC tissues with different differentiation degrees. There were 11 cases of poorly differentiated samples, 20 cases of moderately differentiated samples, and 15 cases of highly differentiated samples. (A) Highly differentiated carcinoma tissue. (B) Moderately differentiated carcinoma tissue. (C) Poorly differentiated carcinoma tissue. The gray particles represent XPC positive expression. The XPC positive expression was gradually increased along with the malignancy of CRC. Scale bar, $100 \mu \mathrm{m}$. ${ }^{*} \mathrm{P}<0.01$ vs. poorly differentiated; ${ }^{\#} \mathrm{P}<0.01$ vs. moderately differentiated. $\mathrm{XPC}$, xeroderma pigmentosum group C; CRC, colorectal carcinoma; IOD, integrated option density.

the SW480. Thus, the SW480 cell line was selected for the following experiments (Fig. 3).

siRNA-XPC increases the chemotherapeutic sensitivity of $S W 480$ cells to cisplatin. siRNA-XPC transfection reduced the level of XPC protein expression in the SW480 cells. However, the XPC protein level was markedly increased in the cells transfected with pcDNA3-XPC compared with the control (Fig. 4).

Prior to transfection, cisplatin significantly inhibited the growth of the tumor cells $(\mathrm{P}<0.05)$. Cisplatin in combination with siRNA-XPC transfection significantly inhibited the cell growth further, compared with cisplatin treatment alone ( $\mathrm{P}<0.05$; Fig 5). In addition, the transfected cells overexpressing XPC exhibited reduced sensitivity to cisplatin compared with cells transfected with the control vector $(\mathrm{P}<0.05)$.

Transfection with siRNA-XPC increases apoptosis of SW480 cells upon treatment with cisplatin. The proportion of cells undergoing apoptosis significantly increased following cisplatin treatment compared with the control $(\mathrm{P}<0.05$; Fig. 6). Notably, siRNA-XPC transfection further increased the proportion of apoptotic cells in the presence of cisplatin. However, when XPC was overexpressed, the apoptotic proportion of the transfected cells was significantly reduced, even in the presence of cisplatin (Fig. 6).

Transfection with siRNA-XPC inhibits the growth of implanted tumors in nude mice. As expected, the growth rate of the implanted tumor was significantly lower in the group inoculated with siRNA-XPC SW480 cells compared with that in the control group at 7, 10, 14 and 21 days after inoculation $(\mathrm{P}<0.05$; Fig. 7). However, the growth rate was significantly

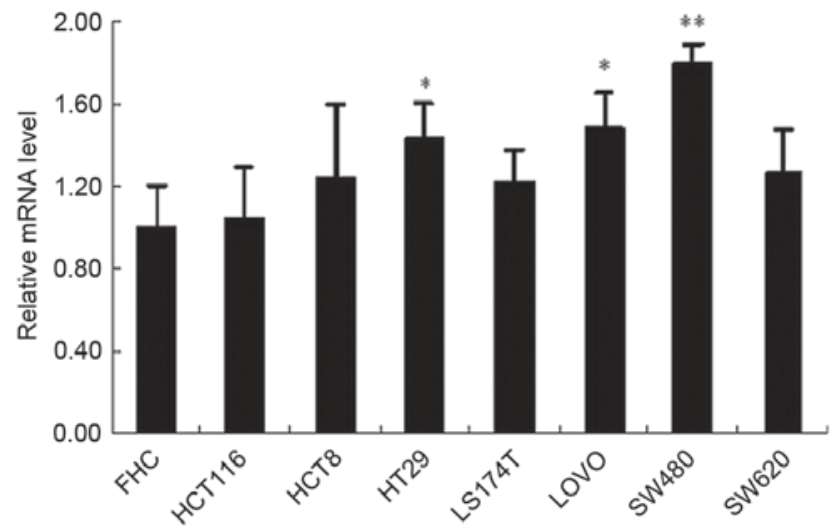

Figure 3. Xeroderma pigmentosum group $\mathrm{C}$ mRNA expression in normal colorectal (FHC) and colorectal cancer (all others) cell lines $(n=3) .{ }^{*} \mathrm{P}<0.05$, ${ }^{* *} \mathrm{P}<0.01$ vs. FHC cells.

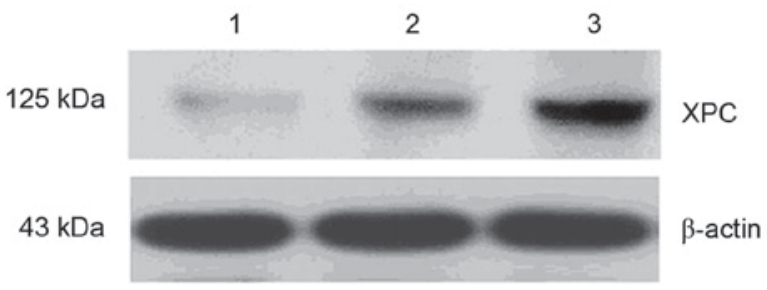

Figure 4. XPC protein expression in SW480 cells following transfection resulting in XPC overexpression or knockdown $(n=3)$. XPC-siRNA or pcDNA3-XPC was transfected into the SW480 cells to knockdown or overexpress XPC, respectively. Western blotting was used to assay the XPC protein level in the transfected cells. Following this, cells were lysed for the western blotting assay. Lane 1, siRNA-XPC-transfected SW480 cells; lane 2, control; lane 3, pcDNA3-XPC-transfected SW480 cells. XPC, xeroderma pigmentosum group C; siRNA, small interfering RNA.

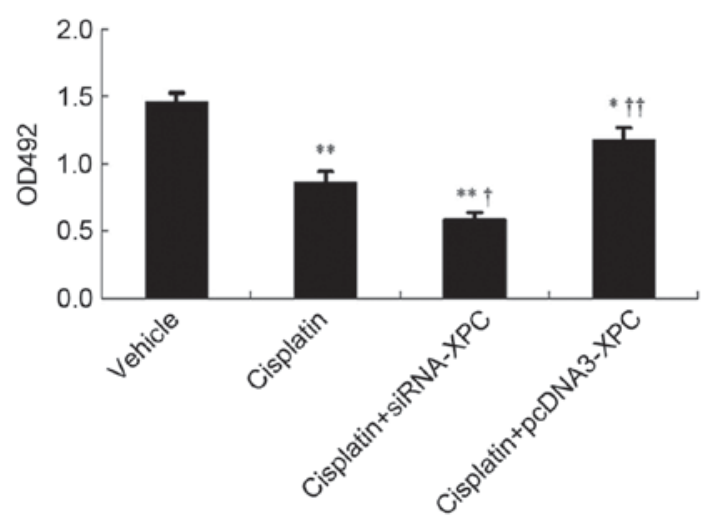

Figure 5. Growth of the transfected cell upon cisplatin treatment $(n=3)$ Cells were inoculated in a 96-well plate and treated with cisplatin for $4 \mathrm{~h}$. Cell susceptibility was measured $24 \mathrm{~h}$ following addition of the tetrazolium salt XTT and measured at $492 \mathrm{~nm} .{ }^{*} \mathrm{P}<0.05,{ }^{* *} \mathrm{P}<0.01$ vs. vehicle; ${ }^{\dagger} \mathrm{P}<0.05$, ${ }^{\dagger} \mathrm{P}<0.01$ vs. cisplatin. OD, optical density; siRNA, small interfering RNA; $\mathrm{XPC}$, xeroderma pigmentosum group $\mathrm{C}$.

faster in the pcDNA3-XPC group compared with that in the control group 10, 14 and 21 day after the inoculation $(\mathrm{P}<0.01$; Fig. 7).

Furthermore, the RTV of the nude mice was smaller in the siRNA-XPC group than that in the control group at 7, 10, 14 and 21 days after inoculation $(\mathrm{P}<0.05)$. Compared with the control 

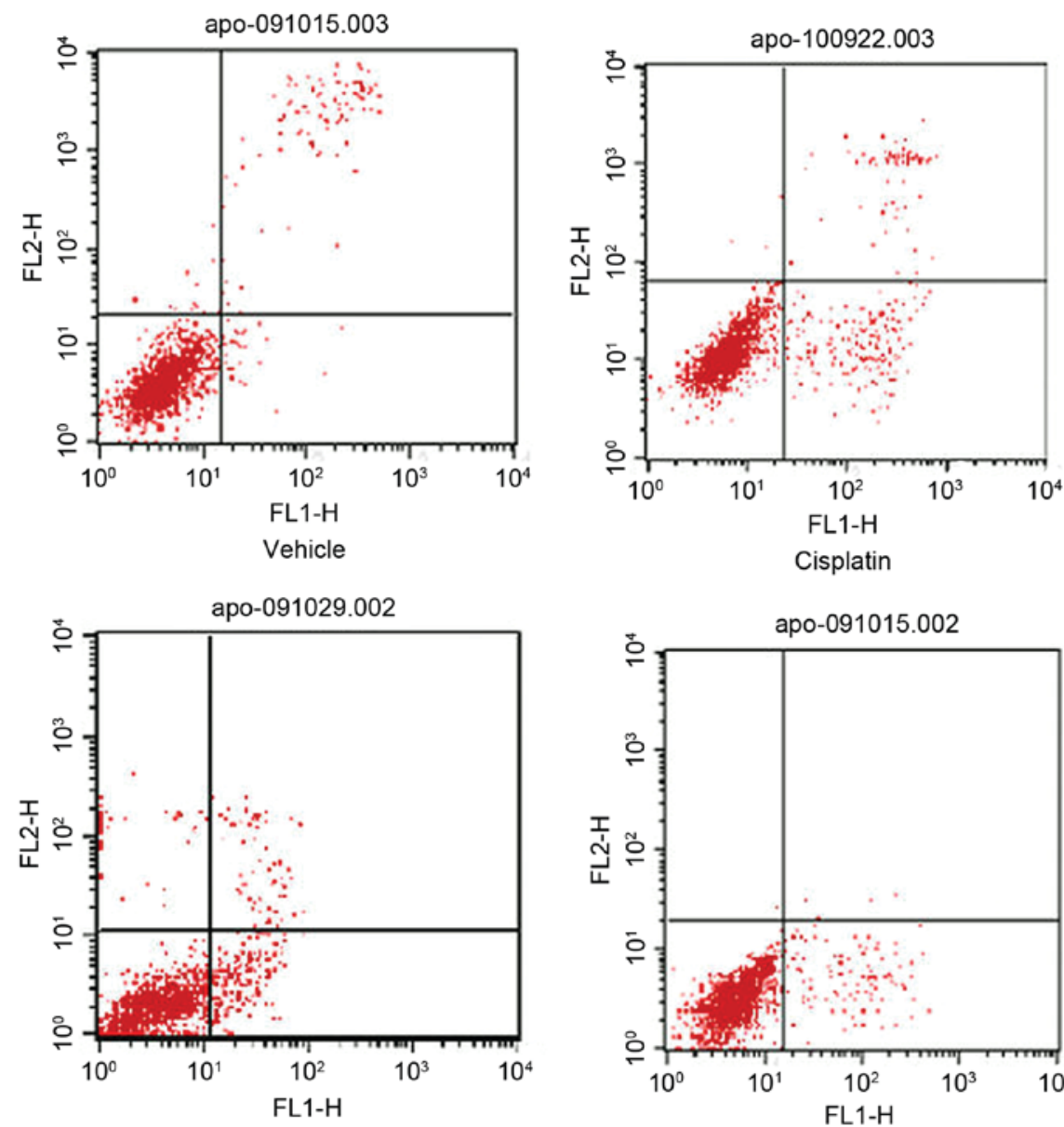

Cisplatin+siRNA-XPC

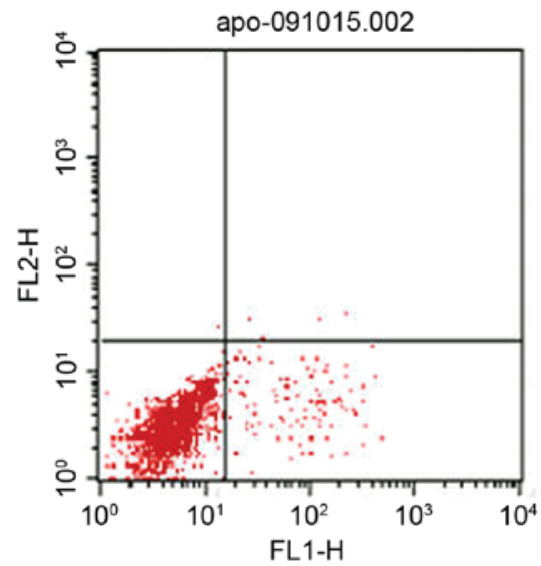

Cisplatin+pcDNA3-XPC

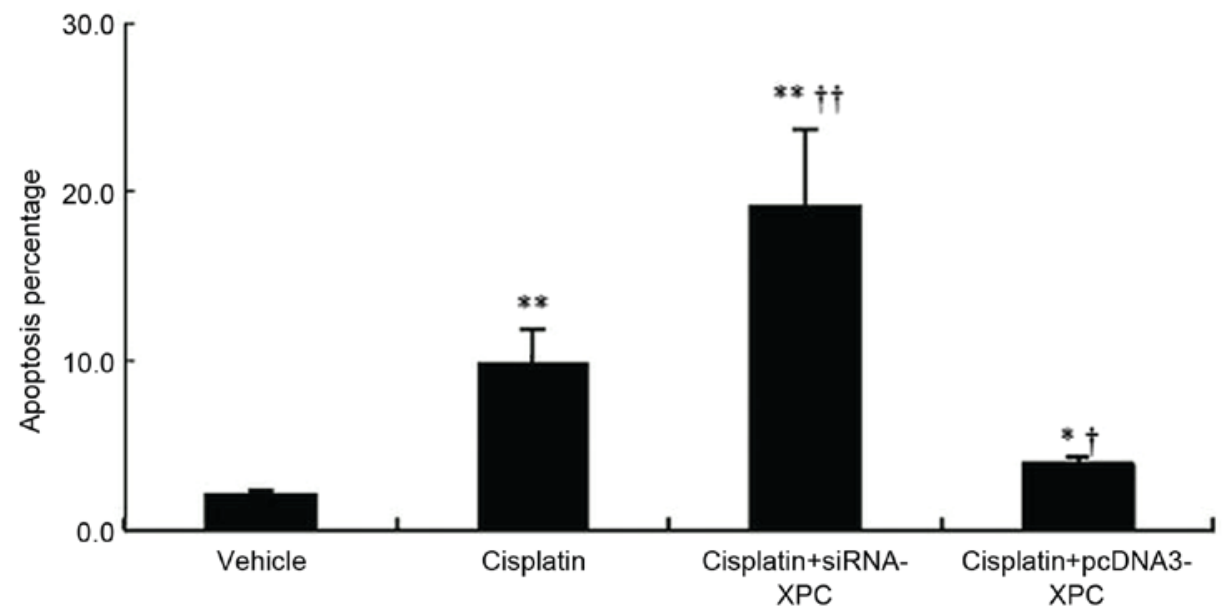

Figure 6. Apoptotic proportion of the transfected cells upon the cisplatin treatment $(\mathrm{n}=3)$. The proportion of apoptotic cells transfected with the indicated vectors was detected using flow cytometry. ${ }^{*} \mathrm{P}<0.05,{ }^{* *} \mathrm{P}<0.01$ vs. vehicle; ${ }^{\dagger} \mathrm{P}<0.05,{ }^{\dagger} \mathrm{P}<0.01$ vs. cisplatin. $\mathrm{XPC}$, xeroderma pigmentosum group C; siRNA, small interfering RNA.

group, the RTV of the pcDNA3-XPC group was significantly increased 14 and 21 days after inoculation $(\mathrm{P}<0.05$; Fig. 7$)$.

Transfection with siRNA-XPC upregulates the level of Bax protein and downregulates that of Bcl-2 in implanted tumor tissue. Inoculation with cells transfected with siRNA-XPC significantly upregulated expression of Bax protein and downregulated that of $\mathrm{Bcl}-2$ in the implanted tumor tissue (Fig. 8). However, the Bcl-2 protein level was higher in the group inoculated with cells transfected with pcDNA3-XPC than that in the control group. These results indicate that siRNA-XPC significantly altered the expression of apoptosis-associated genes expressions in vivo, thereby inhibiting the growth of the implanted tumor (Fig. 8).

\section{Discussion}

Generally, abnormal DNA repair is associated with tumorigenesis and the multi-drug resistance of tumors. NER is a main mechanism for repairing DNA damage caused by 

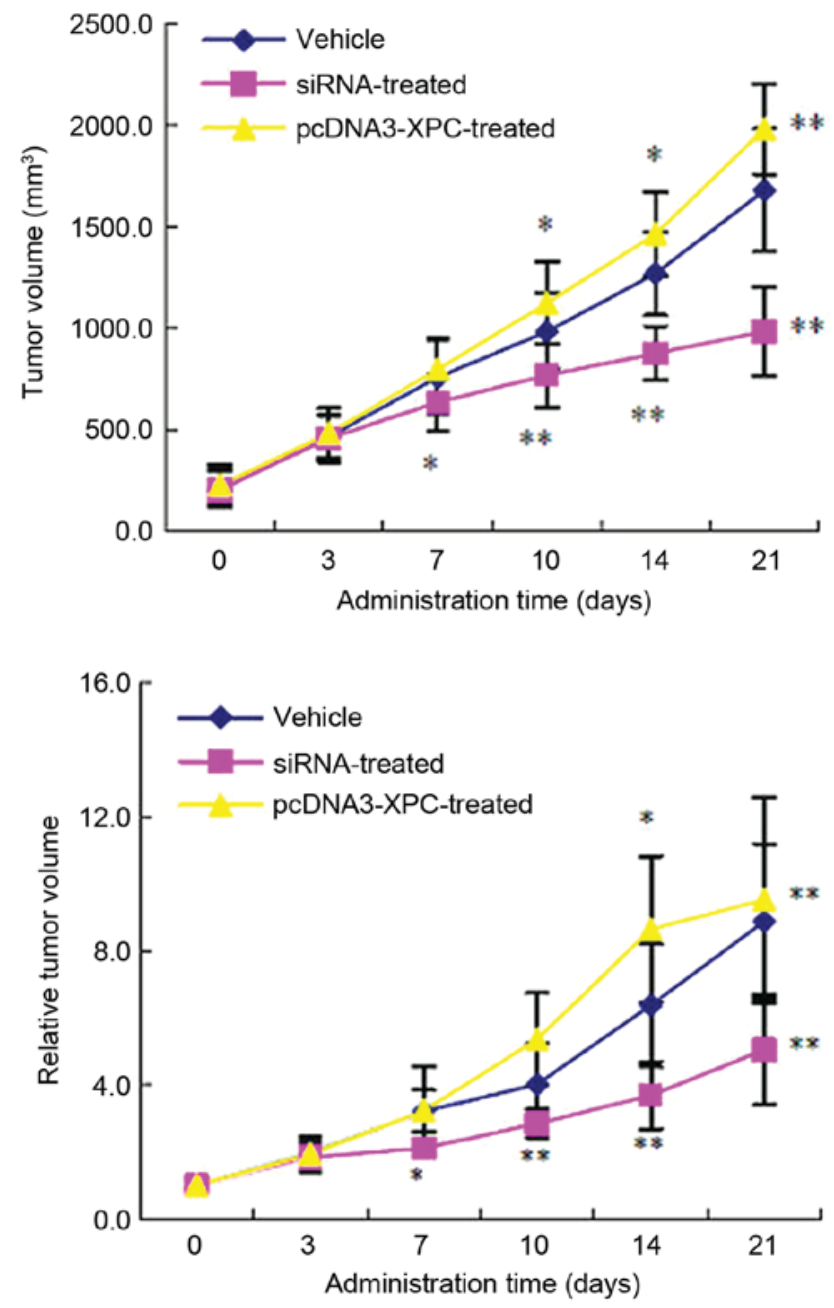

Figure 7. Relative volume of the implanted tumor at specific time points $(\mathrm{n}=6)$ The animals were subcutaneously inoculated with different prepared cell suspension including non-treated, siRNA-treated, and pcDNA3-XPC-treated. The tumor volume was successively observed at specific time points. " $\mathrm{P}<0.05$, ${ }^{*} \mathrm{P}<0.01$ vs. vehicle. XPC, xeroderma pigmentosum group C; siRNA, small interfering RNA.

chemotherapeutics $(10,11)$. Among the large number of NER-associated proteins, XPC serves an important role in DNA damage recognition and speed limitation $(4,5,21)$.

Fautrel et al (5) observed that XPC expression in hepatic carcinoma tissue was significantly higher than that in normal hepatic tissue. In addition, a high expression of XPC was associated with decreased chemotherapeutic susceptibility of hepatic carcinoma (5). Furthermore, XPC silencing was reported to sensitize glioma cells to arsenic trioxide via increased oxidative damage (22).

However, it has been confirmed that the incidence of a variety of tumor types, including CRC, was increased in XPC-deficient mice (23). Chen et al (24) found that there was a direct association between low XPC expression and development of bladder cancer. Recently, it has been revealed that low XPC expression and phenotypic variation were involved in the carcinogenesis of bladder cancer (25). These findings indicated that low XPC expression was associated with the decreased ability to perform NER, which serves an important role in carcinogenesis. The aforementioned studies demonstrate a multiple regulatory role of XPC in DNA damage in tumors.
1

2 3
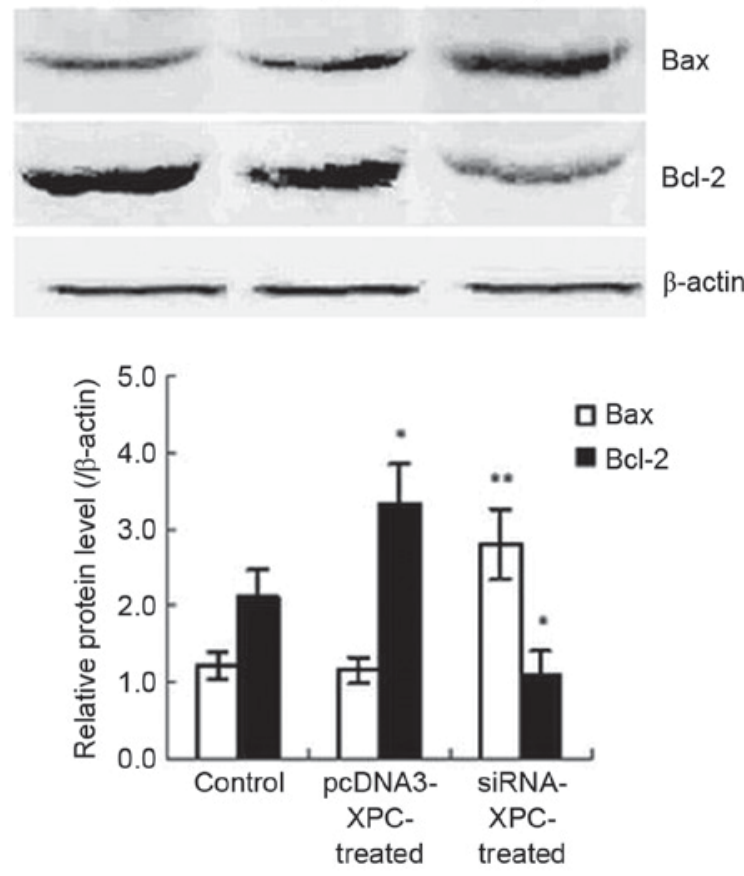

Figure 8. Bax and Bcl-2 protein expressions in the implanted tumors of the nude mice $(\mathrm{n}=6)$. The expression of $\mathrm{Bax}$ and $\mathrm{Bcl}-2$ protein in the transplanted tumor tissue was measured by western blotting. The relative density were calculated to compare expression in the control, siRNA-XPC-treated and pcDNA3-XPC-treated groups. Lane 1, pcDNA3-XPC-treated; lane 2, vehicle control; lane 3, siRNA-XPC-treated. ${ }^{*} \mathrm{P}<0.05,{ }^{* * *} \mathrm{P}<0.01$ vs. control. Bcl-2, B-cell lymphoma-2; Bax, Bcl-associated X; XPC, xeroderma pigmentosum group C; siRNA, small interfering RNA.

H1299, H1355, ovarian cancer cell line 2008, and MDA-MB-231 provided by Shanghai Institutes for Biological Sciences, Chinese Academy of Sciences (Shanghai, China) are susceptible to cisplatin treatment following the knockdown of XPF and ERCC1 (20). Furthermore, the efficacy of the combined knockdown of XPF and ERCC1 was revealed to be better than single siRNA (26). When the XPC-deficient cells were treated with cisplatin, the DNA mutation frequency was 50 times that observed in normal cells (27). When XPC-deficient cells were treated with cisplatin, 486 genes in the XPC-deficient cells exhibited differences in expression at the level of transcription. Notably, among these genes, 297 were associated with tumorigenesis and DNA repair (28). This result indicated that XPC was involved in NER, cell replication and apoptosis. Thus, the abnormal expression of XPC results in a lack of DNA repair ability.

Frequently, XPC is a target for the inactivation in tumors (29). Thus, in the present study siRNA-XPC was transfected into CRC cells. Assessment of these transfected cells revealed that their susceptibility to cisplatin was significantly increased when the XPC gene was silenced. The proportion of apoptotic XPC-deficient cells was significantly increased in the presence of cisplatin when compared with the control. This finding, to a certain degree, agreed with the hypothesis that XPC overexpression participated in the decreased susceptibility of CRC to cisplatin.

XPC, located on chromosome 3 p25, encoding a 940-aminoacid protein, is involved in DNA damage recognition. XPC was first documented in the patients with xeroderma 
pigmentosum (XP). The incidence of skin cancer in patients with XP was 1,000 times higher than that of normal ones following UV exposure, which may be due to functional defect of NER (30).

Furthermore, the proportion of apoptotic cells was significantly decreased when the XPC gene was overexpressed. This result indicated that the overexpression of XPC attenuated the sensitivity of the cancer cells to the chemotherapy. However, the findings of the present study were contradictory to those of Chen et al (24). In their study, they found that bladder cancer HT1197 cells expressing low levels of XPC exhibited a decreased DNA repair capability and were resistant to cisplatin. However, cisplatin-induced apoptosis increased when a XPC cDNA-expression vector was stably transfected into the tumor cells. We hypothesize that this difference may be due to the difference in the repair ability of the XPC gene in different cancer cell lines.

The results of the present study indicate that XPC serves a key role in the chemotherapeutic sensitivity of the CRC cells to cisplatin. XPC overexpression decreased the sensitivity of CRC cells to cisplatin. Conversely, transfection with siRNA-XPC increased the chemotherapeutic sensitivity of these cells, which was associated with the inhibition of cellular growth and promotion of apoptosis in these CRC cells.

\section{Acknowledgements}

Not applicable.

\section{Funding}

No funding was received.

\section{Availability of data and materials}

The datasets used and/or analyzed during the current study are available from the corresponding author on reasonable request.

\section{Authors' contributions}

LX designed all experiments, YZ, JC and YM performed all experiments, and CQ and FS analyzed the experimental results.

\section{Ethics approval and consent to participate}

The clinical and experimental studies were approved by the Ethics Committee of Xinhua Hospital and all patients provided written informed consent.

\section{Consent for publication}

All patients provided written informed consent for the publication of their data.

\section{Competing interests}

The authors declare that they have no competing interests.

\section{References}

1. Wood RD, Mitchell M, Sgouros J and Lindahl T: Human DNA Repair Genes. Science 291: 1284-1289, 2001.

2. Fuss JO and Cooper PK: DNA repair: Dynamic defenders against cancer and aging. PLoS Biol 4: e203-e203, 2006.

3. Iqbal S, Stoehlmacher J and Lenz HJ: Tailored chemotherapy for colorectal cancer: A new approach to therapy. Cancer Invest 22: 762-773, 2004.

4. Maltseva EA, Rechkunova NI, Gillet LC, Petruseva IO, Schärer OD and Lavrik OI: Crosslinking of the NER damage recognition proteins XPC-HR23B, XPA and RPA to photoreactive probes that mimic DNA damages. Biochim Biophys Acta 1770: 781-789, 2007

5. Fautrel A, Andrieux L, Musso O, Boudjema K, Guillouzo A and Langouët S: Overexpression of the two nucleotide excision repair genes ERCC1 and XPC in human hepatocellular carcinoma. J Hepatol 43: 288-293, 2005.

6. Okuda M, Nakazawa Y, Guo C, Ogi T and Nishimura Y: Common TFIIH recruitment mechanism in global genome and transcription-coupled repair subpathways. Nucleic Acids Res 45: 13043-13055, 2017.

7. Spivak G: Nucleotide excision repair in humans. DNA Repair (Amst) 36: 13-18, 2015.

8. Hakem R: DNA-damage repair; the good, the bad, and the ugly. EMBO J 27: 589-605, 2008.

9. Lee SH: Recognition of DNA damage in mammals. J Biochem Mol Biol 34: 489-495, 2001.

10. Bartels CL and Lambert MW: Domains in the XPA protein important in its role as a processivity factor. Biochem Biophys Res Commun 356: 219-225, 2007.

11. Köberle B, Roginskaya V and Wood RD: XPA protein as a limiting factor for nucleotide excision repair and UV sensitivity in human cells. DNA Repair (Amst) 5: 641-648, 2006.

12. Worrillow L, Roman E, Adamson PJ, Kane E, Allan JM and Lightfoot TJ: Polymorphisms in the nucleotide excision repair gene ERCC2/XPD and risk of non-Hodgkin lymphoma. Cancer Epidemiol 33: 257-260, 2009.

13. Zafereo ME, Sturgis EM, Liu Z, Wang LE, Wei Q and Li G: Nucleotide excision repair core gene polymorphisms and risk of second primary malignancy in patients with index squamous cell carcinoma of the head and neck. Carcinogenesis 30: 997-1002, 2009.

14. Huang WY, Berndt SI, Kang D, Chatterjee N, Chanock SJ, Yeager M, Welch R, Bresalier RS, Weissfeld JL and Hayes RB: Nucleotide excision repair gene polymorphisms and risk of advanced colorectal adenoma: XPC polymorphisms modify smoking-related risk. Cancer Epidemiol Biomarkers Prev 15: 306-311, 2006

15. Fan W,Zhang HL and Wu XM: Enhancement effect of nucleotide excision repair gene xeroderma pigmentosun group an antisense RNA on sensitivity of human lung adenocarcinoma cell line A549 to cisplatin. Ai Zheng 24: 403-407, 2005 (In Chinese).

16. Li L, Peterson C and Legerski R: Sequence of the mouse XPC cDNA and genomic structure of the human XPC gene. Nucleic Acids Res 24: 1026-1028, 1996.

17. Legerski RJ, Liu P, Li L, Peterson CA, Zhao Y, Leach RJ, Naylor SL and Siciliano MJ: Assignment of xeroderma pigmentosum group C (XPC) gene to chromosome 3p25. Genomics 21: 266-269, 1994.

18. Livak KJ and Schmittgen TD: Analysis of relative gene expression data using real-time quantitative PCR and the 2(-Delta Delta C(T)) methods. Methods 25: 402-408, 2001.

19. Sugai T, Habano W, Uesugi N, Jiao YF, Nakamura S, Sato K, Chiba T and Ishii M: Molecular validation of the modified Vienna classification of colorectal tumors. J Mol Diagn 4: 191-200, 2002.

20. Maruyama K, Ochiai A, Akimoto S, Nakamura S, Baba S, Moriya Y and Hirohashi S: Cytoplasmic beta-catenin accumulation as a predictor of hematogenous metastasis in human colorectal cancer. Oncology 59: 302-309, 2000.

21. Yang W: Structure and mechanism for DNA lesion recognition. Cell Res 18: 184-197, 2008.

22. Liu SY, Wen CY, Lee YJ and Lee TC: XPC silencing sensitizes glioma cells to arsenic trioxide via increased oxidative damage. Toxicol Sci 116: 183-193, 2010.

23. Nahari D, McDaniel LD, Task LB, Daniel RL, Velasco-Miguel S and Friedberg EC: Mutations in Trp53 gene of UV-irradiated Xpc mutant mice suggest a novel XPC dependent DNA repair process. DNA Repair 3: 379-386, 2004. 
24. Chen Z, Yang J, Wang G, Song B, Li J and Xu LZ: Attenuated expression of xeroderma pigmentosum group $\mathrm{C}$ is associated with critical events in human bladder cancer carcinogenesis and progression. Cancer Res 67: 4578-4585, 2007.

25. Yang J, Xu Z, Li J, Zhang R, Zhang G, Ji H, Song B and Chen Z: XPC epigenetic silence coupled with $\mathrm{p} 53$ alteration has a significant impact on bladder cancer outcome. J Urol 184: 336-343, 2010.

26. Arora S, Kothandapani A, Tillison K, Kalman-Maltese V and Patrick SM: Downregulation of XPF-ERCC1 enhances cisplatin efficacy in cancer cells. DNA Repair (Amst) 9: 745-753, 2010.

27. Chen Z, Xu XS, Yang J and Wang G: Defining the function of XPC protein in psoralen and cisplatin-mediated DNA repair and mutagenesis. Carcinogenesis 24: 1111-1121, 2003.

28. Wang G, Chuang L, Zhang X, Colton S, Dombkowski A, Reiners J, Diakiw A and Xu XS: The initiative role of XPC protein in cisplatin DNA damaging treatment-mediated cell cycle regulation. Nucleic Acids Res 32: 2231-2240, 2004.
29. De Feraudy S, Ridd K, Richards LM, Kwok PY, Revet I, Oh D, Feeney L and Cleaver JM: The DNA damage-binding protein $\mathrm{XPC}$ is a frequent target for inactivation in squamous cell carcinomas. Am J Pathol 177: 555-562, 2010.

30. Hanawalt PC, Ford JM and Lloyd DR: Functional characterization of global genomic DNA repair and its implications for cancer. Mutat Res 544: 107-114, 2003.

(i) (9) This work is licensed under a Creative Commons Attribution-NonCommercial-NoDerivatives 4.0 International (CC BY-NC-ND 4.0) License. 